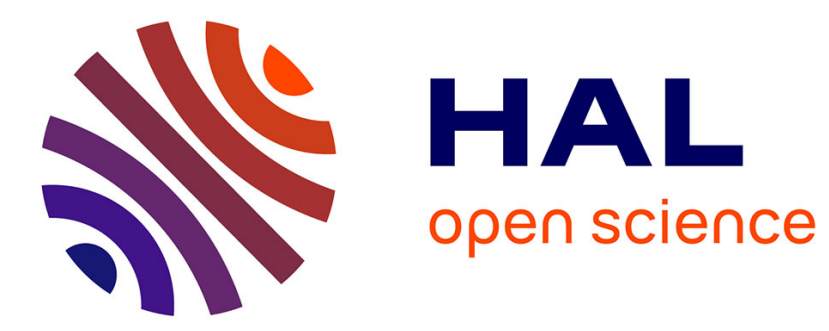

\title{
Piezoresistive CMOS Beams for Inertial Sensing
}

Aboubacar Chaehoi, Laurent Latorre, Pascal Nouet, Salvatore Baglio

\section{To cite this version:}

Aboubacar Chaehoi, Laurent Latorre, Pascal Nouet, Salvatore Baglio. Piezoresistive CMOS Beams for Inertial Sensing. IEEE SENSORS, Oct 2003, Toronto, Canada. pp.451-456, 10.1109/ICSENS.2003.1278978 . lirmm-00269470

\section{HAL Id: lirmm-00269470 https://hal-lirmm.ccsd.cnrs.fr/lirmm-00269470}

Submitted on 3 Apr 2008

HAL is a multi-disciplinary open access archive for the deposit and dissemination of scientific research documents, whether they are published or not. The documents may come from teaching and research institutions in France or abroad, or from public or private research centers.
L'archive ouverte pluridisciplinaire HAL, est destinée au dépôt et à la diffusion de documents scientifiques de niveau recherche, publiés ou non, émanant des établissements d'enseignement et de recherche français ou étrangers, des laboratoires publics ou privés. 


\section{Piezoresistive CMOS Beams for Inertial Sensing}

\author{
A. Chaehoi, L. Latorre, P.Nouet \\ LIRMM, Microelectronic Dept. \\ CNRS / University of Montpellier - France \\ email latorre@lirmm.fr
}

\author{
S. Baglio \\ Dipartimento Elettrico Elettronico e Sistemistico \\ Università di Catania, Italia \\ emailsalvatore.baglio@dees.unict.it
}

\begin{abstract}
This paper presents a preliminary study concerning the use of Front-Side Bulk Micromachining (FSBM) for inertial sensing. When using such a low-cost fabrication approach, the obtained suspended structure do not feature important seismic mass while both CMOS design rules and wet etching do not allow for capacitive detection. Using the standard CMOS polysilicon for piezoresistive detection, obtained results demonstrate that acceptable performance can be reached. In particular, the noise level in polysilicon gauges is low enough to enable a resolution of about $0.5 \mathrm{~g}$ while sensitivity can be improved by designing dedicated on-chip amplification circuitry. Using both an analytical approach and experimental results, a sensitivity of about $27 \mathrm{mV} / \mathrm{g}$ is expected for a CMOS-based sensor.
\end{abstract}

\section{Keywords}

CMOS, MEMS, Accelerometer, Sensor

\section{INTRODUCTION}

Automotive application of inertial sensing such as airbag triggers or seatbelt pretensioners require highly reliable and low-cost sensors. High volume production is also mandatory while requirements for metrological performance are not too tight.

Borrowing the batch fabrication approach from the microelectronic industry, silicon MEMS technology potentially meets those requirements. This is confirmed by the large number of reported works relating to the design of MEMS accelerometers. Reported sensors mostly rely on the use of a suspended seismic mass. The acceleration is therefore obtained by measuring the displacement of this mass. Focusing on monolithic CMOS fabrication approach, solutions differ depending on the way the seismic mass is fabricated and the way the displacement is converted into an electrical signal:

- Bulk etching from the back-side is used to release significant seismic mass, thus improving the sensitivity of the sensor by dealing with large forces. A piezoresistive conversion is usually implemented [1]. This fabrication technique requires an additional specific mask to be aligned on the back-side of the die.

- Surface micromachining on standard CMOS releases thin structures which do not feature an important seismic mass, which is an advantage regarding the reliability. The lack of mass is balanced by the use of a highly sensitive capacitive detection (e.g. combdrives) [2]. A reported fabrication technique makes use of the higher metal layer as a natural mask and requires two etching steps [3]. However, the released structure suffers from curling because of residual stress, which makes the capacitive sensing difficult to succeed without special care $[4,5]$.

- Surface micromachining on specific substrate (e.g. SOI) offers advantage of both heavy suspended mass and a capacitive sensing. CMOS circuitry can be fabricated besides the mechanical part [6], but wafer costs are still high.

For completeness, let us mention a micromachined sensor based on a totally different concept: the convection heat transfer accelerometer [7,8]. Though interesting, such sensors have not been yet implemented on CMOS to our knowledge.

Anisotropic wet etching of CMOS bulk from the front side (FSBM) is the cheapest way to achieve suspended structures leading to monolithic CMOS MEMS. It is a mature technology with a high level of reliability [9]. Apart from economical considerations, obtained structures do not offer important seismic mass while mechanical deformations are sensed using standard non-optimized polysilicon strain gauges. For these reasons, FSBM has never been considered for inertial applications.

This paper investigates the performances of integrated systems making use of such cheap beams. It is organized as follows: the first part presents a preliminary study that motivates this work; in a second part, experimental data is provided using a non-optimized structure; brief modeling is presented in the third part together with prospective simulations of new designs.

\section{PRELIMINARY STUDY}

FSBM post-process allows the fabrication of micrometric mechanical structures using a silicon wafer issued from a standard CMOS industrial process. This MEMS technology can be easily addressed through Multi-Project Wafer services. CMOS is currently a $0.8 \mu \mathrm{m}$ or $0.6 \mu \mathrm{m}$ standard process with two or three metal layers.

According to designer requirements several etching masks can be superimposed to leave the silicon bulk uncovered at the end of the standard CMOS process. Then, the postprocess operates as an anisotropic silicon etching that uses 
the various oxide layers as self-aligned masks. $<100>$ substrate planes can then be etched leaving the $<111>$ planes of silicon substrate unaltered. In that way, suspended structures can be obtained as a heterogeneous stacking of various materials as shown in figure 1 .

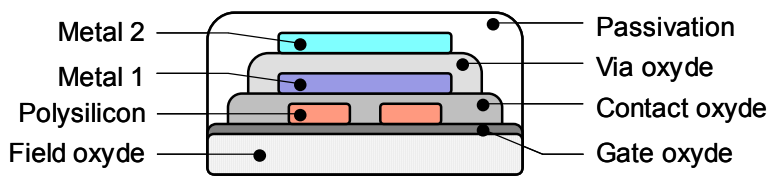
Figure 1. Cross section of a typical
CMOS suspended structure

Table 1. Typical CMOS layer properties

\begin{tabular}{lcc}
\hline \multicolumn{1}{c}{ Layer } & $\begin{array}{c}\text { Thickness } \\
(\mu \mathrm{m})\end{array}$ & $\begin{array}{c}\text { Mass density } \\
\left(\mathrm{kg} / \mathrm{m}^{3}\right)\end{array}$ \\
\hline Field oxide & 0.6 & 2500 \\
Gate oxide & $25.10^{-3}$ & 2500 \\
Polysilicon & 0.4 & 2300 \\
Contact oxide & 0.6 & 2500 \\
Metal 1 & 0.1 & 2700 \\
Via oxide & 1 & 2500 \\
Metal 2 & 1 & 2700 \\
Passivation & 1 & 3100 \\
\hline
\end{tabular}

Table 1 reports for a standard CMOS process typical thicknesses $t_{i}$ and material mass densities $d_{i}$ for the various layers $[10,11]$. According to those values, an estimation of the available seismic mass per surface unit is given by:

$M=\sum t_{i} \cdot d_{i} \approx 14.10^{-3} \mathrm{~kg} / \mathrm{m}^{2}$

In order to evaluate the sensitivity and resolution of FSBM structures for inertial sensing, let's consider the basic accelerometer design presented figure 2 . The seismic mass is provided by a square plate and attached at the end of a cantilever beam. The cantilever bending is therefore converted into an electrical signal by means of two polysilicon strain gauges connected together in a Wheatstone bridge with two resistors of same nominal value. An arbitrary but reasonable set of dimensions is given for the purpose of a numerical example.

According to equation (1) and design parameters, the seismic mass equals $0.56 \mu \mathrm{g}$, therefore providing the cantilever beam with a force per acceleration of about $5.6 \cdot 10^{-9} \mathrm{~N} / \mathrm{g}$. Given that the spring constant of the cantilever is about $k=1.2 \mathrm{~N} / \mathrm{m}$, the resulting deflection approximates $4.6 \mathrm{~nm}$ with an acceleration of $1 \mathrm{~g}$.

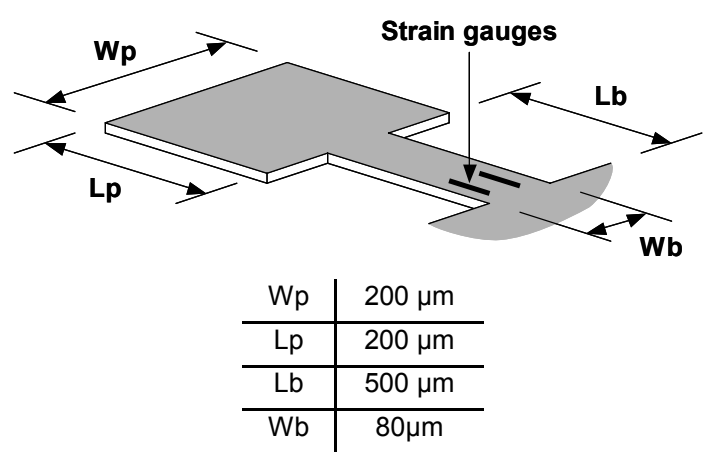

Figure 2. Design example of a FSBM accelerometer

The electromechanical transfer function of the cantilever can be estimated from characterization results. Using a Wheatstone bridge structure with two $1 \mathrm{k} \Omega$ gauges and two $1 \mathrm{k} \Omega$ resistors, the observed voltage swing as a function of the beam bending is $450 \mathrm{~V} / \mathrm{m}$. Consequently, the sensitivity of the proposed sensor is about $2 \mu \mathrm{V} / \mathrm{g}$. Obviously, this sensitivity does not compete with existing devices without considering the opportunity to add an on-chip amplification circuitry.

The resolution of the sensor is estimated considering the noise level at the Wheatstone bridge output. There are two major noise sources: the thermo-mechanical noise of the structure due to thermal agitation of the surrounding gas; and the noise in the four resistors. To estimate the resolution, the mechanical noise may be neglected [12]. The major source of noise in resistors has thermal origins and appears as white noise. This noise spectral density function is therefore a constant over the frequency range, given by :

$V_{\text {noise }}^{2}(f)=4 k T R$

Where $k=1.38 \times 10^{-23} J K^{-1}$ is the Boltzmann's constant, $T$ is the temperature in Kelvin and $R$ is the resistance value in Ohms. The Wheatstone bridge therefore exhibits in thermal noise at room temperature a root spectral density of : $8 n V / \sqrt{H z}$.

We then suppose that the sensor is operated below its resonant frequency, which is approximately given by the ratio :

$f_{\text {res }}=\frac{1}{2 \pi} \sqrt{\frac{k}{M}}$

For the proposed example, this frequency is $7.4 \mathrm{kHz}$. Assuming that the sensor signal is ideally filtered to reject frequencies above $f_{\text {res }}$, we finally obtain a total noise voltage of $0.68 \mu \mathrm{Vrms}$. Using the previously calculated sensitivity of $2 \mu \mathrm{V} / \mathrm{g}$, the resolution of the proposed sensor approximates $0.5 \mathrm{~g}$ before amplification. Depending on the application requirements, this resolution can even be improved by means of further signal filtering.

This preliminary work clearly demonstrates that low-cost CMOS beams meet the basic requirements for $\mathrm{Z}$-axis inertial sensing and encourage us for further investigation. 


\section{EXPERIMENTAL STUDY}

\section{The Test Device}

The performance of CMOS in an accelerometer application has been experimentally investigated using a previously designed (and so available) device.

This circuit, which is shown in figure 3 , features a UShaped cantilever structure together with an amplification and filtering circuit. Although this is not the point of the paper, note that the U-Shaped device has been initially developed for the purpose of magnetic field measurement [13]. Since it can be actuated by means of the Lorentz force (static mode and dynamic mode), it also enables several characterization. Mechanical and electrical parameters of this device have therefore been extensively studied [14], providing a key support to the current work. Most significant device parameters are summarized in table 2.

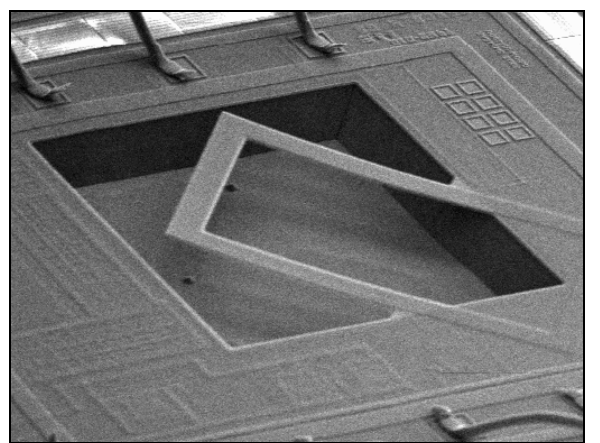

Figure 3. The test-vehicle used for experiments.

Table 2. Main parameters of the test vehicle

\begin{tabular}{lc}
\hline U-Shape dimensions & $520 \times 520 \mu \mathrm{m}$ \\
Beam width & $80 \mu \mathrm{m}$ \\
Mass & $8.410^{-10} \mathrm{~kg}$ \\
Spring constant & $2.4 \mathrm{~N} / \mathrm{m}$ \\
Damping factor & $7.210^{-7} \mathrm{Ns} / \mathrm{m}$ \\
Natural frequency & $8.3 \mathrm{kHz}$ \\
Quality factor & 66 \\
Amplifier gain (programmable) & $7 / 700$ \\
Output voltage with respect & $3.2 / 320 \mathrm{mV} / \mu \mathrm{m}$ \\
to beam deflection & \\
\hline
\end{tabular}

\section{Experimental Setup}

The experimental setup is shown in figure 4. The packaged test chip is attached to a one-axis shaker which can apply sine-wave vibrations with magnitudes ranging from $0.1 \mathrm{~g}$ up to $20 \mathrm{~g}$ at various frequencies up to $200 \mathrm{~Hz}$. Shocks can be also applied in a range from $200 \mathrm{~g}$ to $2000 \mathrm{~g}$.
The output signal of the test chip is captured by an oscilloscope, the latter being triggered by means of the shaker built-in accelerometer. As no characterization data was available for the shaker, a preliminary calibration has been performed using an ADXL150 accelerometer.

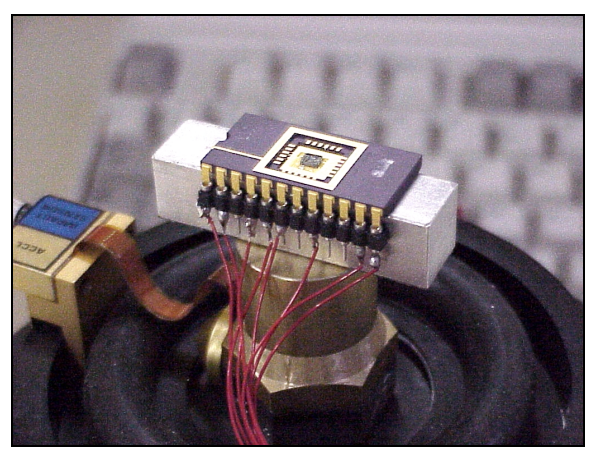

Figure 4. Close-up view of the test chip attached to the shaker

This setup has been used to study the sensor response to both shocks and sine wave accelerations. The results are presented hereafter.

\section{Shock Response}

Shocks have been applied on the sensor from $200 \mathrm{~g}$ to $2000 \mathrm{~g}$. At first, note that $100 \%$ of our devices perfectly survived all these tests. In figure 5, the sensor response to a $500 \mathrm{~g}$ shock is presented. The thin line is the signal measured from the shaker built-in sensor whereas the thick line corresponds to the test chip response. The frequency of the pseudo-periodic oscillations matches the U-Shape natural frequency (i.e. $8.3 \mathrm{kHz}$ ). It therefore confirms that the suspended beam detects shocks. The amplitude of the first peak (about $1.9 \mathrm{~V}$ ) corresponds to a beam deflection of about $6 \mu \mathrm{m}$.

The linearity has been studied in a short range, left-limited at $200 \mathrm{~g}$ by the shaker capability and right-limited at $700 \mathrm{~g}$ by the amplification circuitry. Beyond this shock amplitude, electronic amplifier saturates. In this window, considering the magnitude of the first peak the test device exhibits a linear behavior. In figure 6 , the sensitivity to shocks is found around $4 \mathrm{mV} / \mathrm{g}$. Given that the cantilever behaves like a second-order mechanical system, the first-peak magnitude is about twice the static response. Consequently, the static sensitivity is expected around $2 \mathrm{mV} / \mathrm{g}$. 


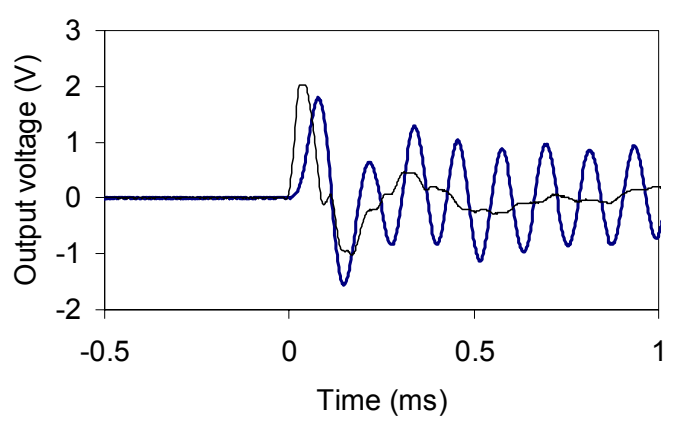

Figure 5. Test chip response to a $500 \mathrm{~g}$ shock

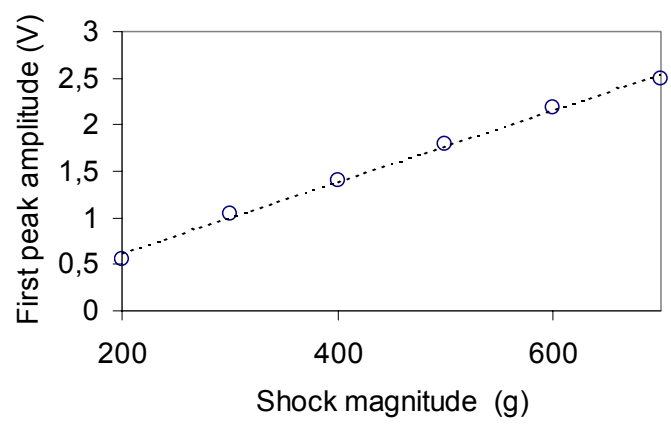

Figure 6. Sensitivity of the test chip to shocks (based on the magnitude of the first peak)

\section{Vibration Response}

Small accelerations have been applied as sinusoidal vibrations. In figure 7, a vibration of $10 \mathrm{~g}$ in magnitude is provided by the shaker at $100 \mathrm{~Hz}$, while the sensitivity is studied and reported in figure 8. Again, the test chip exhibits good linearity for low level accelerations. The slope of the characteristic confirms the previously established sensitivity of about $2 \mathrm{mV} / \mathrm{g}$.

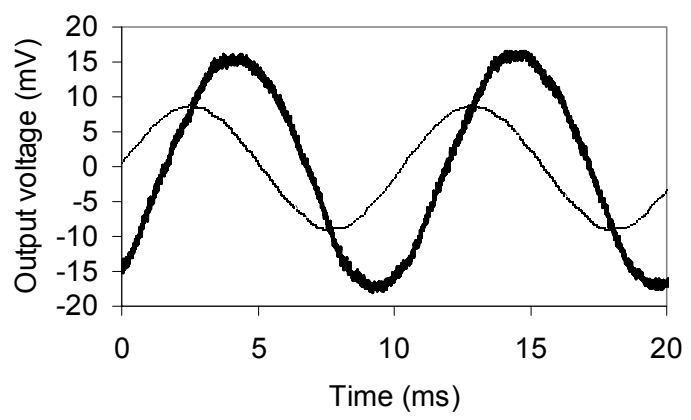

Figure 7. Test chip response to a $10 \mathrm{~g}$ vibration @ $100 \mathrm{~Hz}$

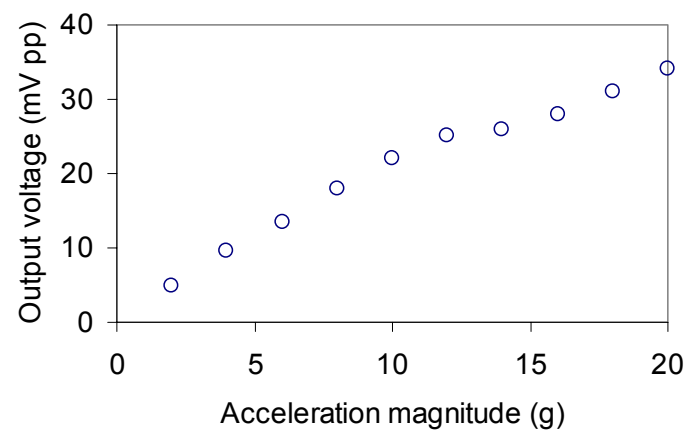

Figure 8. Sensitivity of the test chip to $100 \mathrm{~Hz}$ vibrations

Having no information concerning the built-in shaker sensor, the phase difference visible in figure 7 has not been analyzed up to now.

Finally, a resolution of $0.5 \mathrm{~g}$ has been measured at $100 \mathrm{~Hz}$ $(\mathrm{SNR}=1)$. Note, however, that this resolution is obtained using additional filtering capability of the oscilloscope (averaging mode), thus limiting the signal bandwidth.

\section{DESIGN \& SIMULATIONS}

\section{Design Methodology}

The suspended beam is modeled with a second order mechanical system including a spring $k$, a mass $M$ and a damper $D$. Such a system is easily described with a set of differential equations taking either high-level characterized parameters $(k, M, D)$, or low-level foundry-given parameters such as material mass densities, Young's modulus and so on.

Having very few exact information from the foundry, we use experimental data to parameter high level models. Those models are finally integrated into the standard ASIC design flow by means of an Analog Hardware Description Language (AHDL). Doing so, system-level simulations are performed using any analog simulator such as SPICE, taking into account both the sensing part and the associated electronic circuitry.

\section{Simulation of new structures}

There are two simple ways for improving the sensitivity of the FSBM suspended structures :

- By increasing the seismic mass

- For a given force, by increasing the stress level in the piezoresistive gauges, i.e. by decreasing the beam stiffness. 
It subsequently comes that the sensor sensitivity depends on the ratio $m / k$. For obvious reason of fabrication yield, this ratio has to be limited to reasonable values.

Based on the beam depicted in figure 2, now called the "TShape" structure, two new sensors have been designed and sent for fabrication. The only difference between T-Shape "A" and T-Shape " $\mathrm{B}$ " is the dimension $W b$ (beam width). Therefore, the sensitivity of T-Shape " $\mathrm{B}$ " is expected to be twice the sensitivity of T-Shape "A", while T-Shape "A" should take advantage from a better fabrication yield.

Table 3 summarizes the calculated design features of those devices. Note that an instrumentation amplifier with a programmable gain has been integrated beside the mechanical parts.

Table 3. Design features of the T-Shaped structures

\begin{tabular}{lcc}
\hline & T-Shape A & T-Shape B \\
\hline $\mathrm{Lb} \times \mathrm{Wb}(\mu \mathrm{m})$ & $480 \times 80$ & $480 \times 40$ \\
$\mathrm{Lp} \times \mathrm{Wp}(\mu \mathrm{m})$ & $280 \times 280$ & $280 \times 280$ \\
Spring constant $(\mathrm{N} / \mathrm{m})$ & 0.61 & 0.28 \\
Mass $(\mathrm{kg})$ & $9.610^{-10}$ & $9.110^{-10}$ \\
Damping factor $(\mathrm{Ns} / \mathrm{m})$ & $10.410^{-7}$ & $8.710^{-7}$ \\
Natural Frequency $(\mathrm{kHz})$ & 4 & 2.8 \\
Quality factor & 23 & 19 \\
Amplification & $10 / 100 / 1000$ & $10 / 100 / 1000$ \\
\hline
\end{tabular}

Figure 3 compares the simulated sensitivity of the T-Shape cantilevers with the measured sensitivity of the test chip (U-Shape). Final sensitivities of $13,3 \mathrm{mV} / \mathrm{g}$ for T-Shape "A" and 27,87mV/g for T-Shape "B" are estimated.

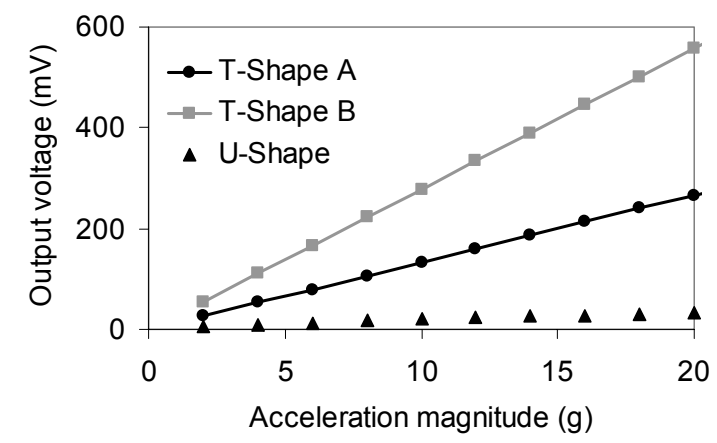

Figure 9. Simulated sensitivity of T-Shape devices

The resolution is computed by means of a noise simulation. The equivalent noise spectral density is plotted for both cantilevers in figure 10 . Since the output noise is nearly the same for the two devices, the equivalent input noise for $\mathrm{T}$ Shape "B", which is two times more sensitive, is half the input noise of T-Shape " $A$ ". When integrating the input noise from DC up to the cantilevers resonant frequencies, we obtain a resolution of $0.8 \mathrm{~g}$ for T-Shape "A" and $0.37 \mathrm{~g}$ for T-Shape "B". Given that most of the noise comes from the implemented amplifier (Op-Amp based), this resolution can be improved by designing a noise-optimized amplifier. Based on the preliminary results the resolution of T-Shape " $\mathrm{B}$ " (measured after the Wheatstone bridge) is expected below $0.1 \mathrm{~g}$.

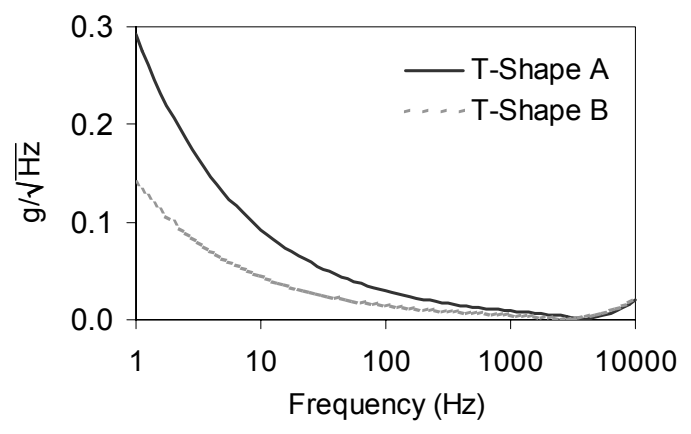

Figure 10. Equivalent input noise spectral
density of T-Shape devices

\section{CONCLUSION}

This paper demonstrated that low-cost CMOS suspended structures can be used for inertial sensing. Although not optimized in terms of available seismic mass or gauge factor, the piezoresistive CMOS beams exhibit a low noise level, thus enabling reasonable resolution. In the context of fully monolithic fabrication approach, electronic circuitry can be designed to improve the sensor performance.

Using an available test chip, a sensitivity of $2 \mathrm{mV} / \mathrm{g}$ has been measured while resolution can be estimated around $0.5 \mathrm{~g}$. Based on this encouraging result, two new cantilevers have been designed and simulated. A final sensitivity of about $27.8 \mathrm{mV} / \mathrm{g}$ has been simulated.

The FSBM structures are appropriate to Z-axis acceleration measurement. They therefore offer a complementary and low-cost issue to in-plane sensors such as comb-drives or sensors based on convection heat transfer.

\section{REFERENCES}

[1] H. Takao, H. Fukumoto, and M. Ishida, "A CMOS Integrated Three-Axis Accelerometer Fabricated With Commercial Submicrometer CMOS Technology and BulkMicromachining", IEEE Transactions On Electron Devices, Vol. 48, No. 9, September 2000.

[2] Analog Devices, " $\pm 5 g$ to $\pm 50 \mathrm{~g}$, Low Noise, Low Power, Single/Dual Axis iMEMS Accelerometer", ADXL150/ ADXL250 datasheet.

[3] J. M. Bustillo, R. T. Howe, R. S. Muller, "Surface Micromachining For Microelectromechanical Systems", Proc of the IEEE, vol.86, nº , August 1998. 
[4] H.Xie and G K.Fedder, "A CMOS Z-axis capacitive Accelerometer with comb-finger sensing", IEEE MEMS'2002, pp. 496-501.

[5] H. Luo and G. K Fedder, L. R. Carley, "A $\operatorname{ImG~Lateral~}$ CMOS-MEMS Accelerometer", IEEE MEMS'2000, The Thirteenth Annual International Conference on , 23-27 Jan. 2000, pp. $502-507$.

[6] L. Zimmerman, J. Ph. Ebersohl, F. Le Hung, J. P. Berry, F. Baillieu, P. Rey, B. Diem, S. Renard, P. Caillat, "Airbag Application: A Microsystem Including A Silicon Capacitive Accelerometer, CMOS Switched Capacitor Electronics And True Self-Test Capability", Sensors and Actuators A 46-47 (1995), pp. 190-195.

[7] F. Mailly, A. Giani, A. Martinez, R. Bonnot, P. TempleBoyer, A. Boyer, "Micromachined Thermal Accelerometer" Sensors and Actuators A 103 (2003).

[8] A. M. Leung, J. Jones, E. Czyzewska, J. Chen, B. Woods, "Micromachined Accelerometer Based on Convection Heat Transfer", IEEE MEMS'1998, The Eleventh Annual International Workshop on , 25-29 Jan. 1998, pp. 627-630.
[9] M. Dardalhon, V. Beroulle, L. Latorre, P. Nouet, G. Perez, J.M. Nicot, C. Oudea, "Reliability Analysis of CMOS MEMS structures obtained by Front Side Bulk Micromachining", Microelectronics Reliability, Volume 42, Issues 9-11, September-November 2002, pp. 1777-1782.

[10] Austria Mikro Systeme, "0,8 $\mu \mathrm{m}$ CMOS Process Parameters" AMS 0,8 $\mu \mathrm{m}$ datasheet.

[11] K. R. Petersen, "Silicon As Mechanical Material", Proc. of the IEEE, vol.70, 1982.

[12] T.B. Gabrielson, "Mechanical-Thermal Noise in Micromachined Acoustic and Vibration Sensors", IEEE Transaction on Electron Devices, Vol. 40, n5, May 1993.

[13] V. Beroulle, L. Latorre, P. Nouet, "Micromachined CMOS Magnetic Field Sensors with Low-Noise Signal Conditioning", IEEE MEMS'2002, Las-Vegas, USA, Jan. 20-24, 2002, pp.256-259.

[14] L. Latorre, V. Beroulle, M. Dardalhon, P. Nouet, F. Presseq, C. Oudea, "Characterization of CMOS MEMS Technology Scatterings", Proc. ISTFA 2001, Santa-Clara (CA), USA, Nov. 11-15, 2001, pp. 373-377. 